\title{
Characteristics of Malignant Eyelid Basal Cell Carcinoma in Cicendo Eye Hospital Bandung from 2013 to 2015
}

\author{
Yee She Hui, ${ }^{1}$ Raden Angga Kartiwa, ${ }^{2}$ Resti Gradia Dwiwina ${ }^{3}$ \\ ${ }^{1}$ Faculty of Medicine Universitas Padjadjaran, ${ }^{2}$ Department of Ophthalmology Faculty of \\ Medicine, Universitas Padjadjaran/Cicendo Eye Hospital Bandung, ${ }^{3}$ Department of Anatomy, Cell \\ Biology and Physiology Faculty of Medicine Universitas Padjadjaran
}

\begin{abstract}
Background: Basal cell carcinoma (BCC) has been proved to have the highest incidence among eyelid malignancies. Basal cell carcinoma is the most common invasive cancer in humans. It is capable of causing extensive tissue destruction. The aim of the study was to identify the characteristics of adult patients with malignant eyelid BCC in Cicendo Eye Hospital Bandung.

Methods: A descriptive retrospective study was conducted to determine the characteristics of adult patients with malignant eyelid BCC in Cicendo Eye Hospital Bandung from March 2013 to October 2015. Age and sex distribution of the lesions, location and histopathological results of the tumors were stratified as variables. The inclusion criteria were patients over age of 20, histopathologically diagnosed with periocular BCC.

Results: A total of 37 cases histopathologically diagnosed with periocular BCC were evaluated. Females had a slight predominance. The mean age was 61.7 years. The most common site was on the lower lid. The tumors occurred more on the left side. The most common histological subtype was represented by solid growth pattern.

Conclusions: The majority of periocular BCC cases occur in females and elderly. Most tumors develop on the lower lid with a left-side preference and have a solid growth pattern histologically. [AMJ.2017;4(1):14851]

Keywords: Basal cell carcinoma, characteristics, malignant eyelid tumor
\end{abstract}

\section{Introduction}

Incidence rates of skin cancer have risen dramatically over the last decade. The incidence has increased with decreased latitude and most tumors develop on sun exposed areas of the head and neck. As the earth's protective ozone shield continues to thin, further increases in the incidence of skin cancer can be predicted. ${ }^{1}$

Approximately 90 percent of skin cancers arise to head and neck and 10 percent from them occur in the eyelids. ${ }^{2}$ Histopathological diagnosis and clinical correlation have been examined in published case reviews. Many studies overseas have shown that basal cell carcinoma (BCC) represents the most common malignant eyelid tumor, followed by squamous cell carcinoma, sebaceous gland carcinoma and/or malignant melanoma. ${ }^{2-7}$ Basal cell carcinoma is the most common invasive cancer in humans. It is a slowly enlarging, locally invasive neoplasm arising from epidermal basal cells and is capable of extensive tissue destruction. ${ }^{1,4}$ Therefore, the ability to identify characteristics of the tumor is extremely important.

This study focused solely on malignant eyelid BCC in Cicendo Eye Hospital Bandung in the period of March 2013 to October 2015. In addition, age and sex distribution of the lesions, location and histopathological results of the tumors were evaluated.

\section{Methods}

This study was conducted from October to This study retrospectively reviewed the medical records specific to periocular BCC from March 2013 to October 2015 in Cicendo Eye Hospital Bandung. A total sampling method was used for data collection. Eligible were patients over

Correspondence: Yee She Hui, Faculty of Medicine, Universitas Padjadjaran, Jalan Raya Bandung-Sumedang Km.21, Jatinangor, Sumedang, Indonesia, Phone: +6281802264493 Email: yeeshehui@gmail.com 
20 years of age, histopathologically diagnosed with periocular BCC. Exclusion criteria were medical records without histopathological confirmation. Patients' demographics, location and histopathological results of the tumors were collected and recorded. Age and sex distribution of the lesions, location and histopathological results of the tumors were then analyzed and tabulated. This study received approval from the Health Research Ethics Committee of Cicendo Eye Hospital Bandung.

\section{Results}

A total of 37 adult patients with periocular BCC histopathologically diagnosed from March 2013 to October 2015 were identified.

The distribution related to patients' characteristics was presented (Table 1). Related to gender, 19 cases were female and 18 cases were male patients. It was a little preponderance for the female patients. The most common age group affected was between 51-60 years. The mean age of patients
Table 1 Distribution Related to Patients' Characteristics

\begin{tabular}{lc}
\hline \multicolumn{1}{c}{$\begin{array}{c}\text { Patients' } \\
\text { Characteristics }\end{array}$} & Frequency \\
\hline Gender & \\
Male & 18 \\
Female & 19 \\
Age Group (Years) & \\
$21-30$ & 1 \\
$31-40$ & 2 \\
$41-50$ & 3 \\
$51-60$ & 12 \\
$61-70$ & 7 \\
$71-80$ & 9 \\
$81+$ & 3 \\
\hline
\end{tabular}

group was 61.7 years with range between 26-90-year-old.

The distribution related to tumors' characteristics was presented (Table 2).

Table 2 Distribution Related to Tumors' Characteristics

\begin{tabular}{lc}
\hline \multicolumn{1}{c}{ Tumors' Characteristics } & Frequency \\
\hline Periocular region & 18 \\
Lower lid & 8 \\
Upper lid & 0 \\
Medial canthus & 1 \\
Lateral canthus & 4 \\
Combined* & 6 \\
Unspecified & \\
Side & 7 \\
Right & 23 \\
Left & 7 \\
Unspecified & \\
Subtype & 16 \\
Solid & 5 \\
Pigmented & 1 \\
Nodular & 3 \\
Basosquamous & 3 \\
Combined** & 4 \\
Unspecified & 8 \\
\hline Note: $*$ The combined involvements contained two simultaneous involvements of upper and lower lid; simultaneous \\
involvement of upper lid, lower lid, and medial canthus; and simultaneous involvement of lateral canthus and lower lid, \\
The combined involvements were all simultaneous involvements of solid and pigmented subtypes.
\end{tabular}


Regarding the site of tumors, 18 cases of the tumors were located on the lower lid, followed by 8 cases on the upper lid, and only 1 case on the lateral canthus. There were 4 cases involved more than one region. Of the cases, periocular BCC occurred less on the right side and more on the left. The most common histological subtype was represented by solid growth pattern, accounting for 16 cases. Pigmented BCC was identified in 5 cases, followed by basosquamous with 3 cases and nodular with only 1 case. There were 4 cases consisting of more than one subtype.

\section{Discussion}

There is a significant consideration in this study in which data are retrieved from the pathology logs of Cicendo Eye Hospital Bandung due to limitations in medical records of BCC. Nevertheless, this study still shows a compelling overview of data that is important for ophthalmologist and other physicians.

In this study, the incidence of BCC is more predominant in females than males. This finding is in contrast to other studies which have been conducted in other countries. ${ }^{2,5}$ For example, in a retrospective study carried out in San Francisco, the data demonstrated a significant difference in number of men diagnosed over women with BCC. ${ }^{5}$ In addition, in another study carried out in Oradea, demonstrated an equal male over female distribution. $^{2}$ Solid reasons for BCC having slight predominance for the females are unable to be predicted. This may be associated with the higher use of sunscreen by women in developed countries comparing to women in developing countries, which resulting in this dissimilarity finding. However, both of these studies had a patient's mean age of over 60, which were highly consistent with the mean age of 61.7 years in our study. ${ }^{2,5}$ Thus, we can conclude that, an older age can be a solid contributing factor to the development of BCC of the eyelids.

In agreement with other studies, the majority of BCC are located on the lower lid. ${ }^{6,8}$ This statement can be affirmed in accordance with a retrospective study carried out in Australia for a period of seven years (2006 to 2012) which have discovered BCC occurring more frequently on the lower lid. ${ }^{6}$ An early study in central India also demonstrated similar finding. ${ }^{8}$ While studies reported from Australia and Israel revealed BCC tend to have left- or right-side preferences due to greater sun exposure on that side during driving, our study has shown an inconsistent outcome.6,9 This phenomenon may be explained by the vehicle composition in Indonesian cities with a threefold proportion of motorcycles than cars. ${ }^{10}$ Histologically, the most common subtype is represented by solid growth pattern. This finding is particularly constant with previous study in Oradea while interestingly, most other studies describing nodular BCC as the most common histological type. .,6,9,11 $^{2}$

There are limitations in this study where this study may not represent the entire Bandung population. Nonetheless, this study provides a compelling overview of BCC as a basis of upcoming research and essential information for physicians and the community.

In conclusion, there is slight preponderance for the females in periocular BCC. Most of the patients are older. Additionally, the most common site of tumors is on the lower lid. The tumors show left-side preference. Lastly, the most common BCC histological subtype occurring in the periocular region is represented by solid growth pattern. This study may increase the awareness of periocular BCC among medical professionals and the community and aids in early diagnosis which favors a better prognosis.

\section{References}

1. Longo D, Fauci A, Kasper D, Hauser S, editors. Harrison's principles of internal medicine. 18thed. New York: McGraw-Hill Professional; 2011.

2. Coroi MC, ROŞCA E, MUȚIU G, Coroi T, Bonta M. Eyelid tumors: histopathological and clinical study performed in County Hospital of Oradea between 2000-2007. Rom J MorpholEmbryol. 2010;51(1):1115.

3. Bagheri A, Tavakoli M, Kanaani A, Zavareh RB, Esfandiari H, Aletaha M, et al. Eyelid masses: a 10-year survey from a tertiary eye hospital in Tehran. Middle East Afr JOphthalmol. 2013;20(3):187-92.

4. Hussain I, Khan FM, Alam M, Khan BS. Clinicopathological analysis of malignant eyelid tumours in north-west Pakistan. J Pak Med Assoc. 2013;63(1):25-7.

5. Paul S, Vo DT, Silkiss RZ. Malignant and benign eyelid lesions in San Francisco: study of a diverse urban population. Am J Clin Med. 2011;8(1):40-6.

6. Wu A, Sun MT, Huilgol SC, Madge S, Selva D. Histological subtypes of periocular basal cell carcinoma. J Clin Exp Ophthalmol. 2014;42(7):603-7. 
7. Pombejara FN, Tulvatana W, Pungpapong K. Malignant tumors of the eye and ocular adnexa in Thailand: a six-year review at King Chulalongkorn Memorial Hospital. Asian Biomed (Res Rev News). 2010;3(5):551-5.

8. Jahagirdar SS, Thakre TP, Kale SM, Kulkarni H, Mamtani M. A clinicopathological study of eyelid malignancies from central India. Indian J Ophthalmol. 2007;55(2):109-12.

9. Ben Simon GJ, Lukovetsky S, Lavinsky $\mathrm{F}$, Rosen N, Rosner M. Histological and clinical features of primary and recurrent periocular basal cell carcinoma. ISRN Ophthalmol. 2012;2012:1-5.

10. Putranto LS, Prasetijo J, Eka NLPS, editors. Vehicle composition in Indonesia and Malaysia. Proceedings of the Eastern Asia Society for Transportation Studies. 2013;9.

11. Ho S, Brown L, Bamford M, Sampath R, Burns J. 5 years review of periocular basal cell carcinoma and proposed follow-up protocol. Eye. 2013;27(1):78-83. 